Горбань Владимир Сергеевич

кандидат юридических наук, старший научный сотрудник сектора философии права, истории и теории государства и права Института государства и права РАН

\section{ВЛИЯНИЕ И ИНТЕРПРЕТАЦИЯ ПРАВОВЫХ ВЗГЛЯДОВ Р. ИЕРИНГА В СОЧИНЕНИЯХ О.В. ХОЛМСА}

Аннотация:

В статье исследуется проблема влияния и интерпретации правовых взглядов одного из наиболее известных немецких правоведов XIX в. P. Иеринга в творчестве О.В. Холмса - основателя интеллектуального движения в американской юридчческой мысли, которое, хотя и не было однородным, в целом именовалось как «правовой реализм». Анализ оригинальных текстов сочинений мыслителей показывает существенные моменты сходства их взглядов, а также модификацию и развитие О.В. Холмсом основных сюжетов и профилей обсуждения правовой проблематики, характерных для правовой парадигмы немецкого правоведа. При этом подчеркивается, что в творчестве О.В. Холмса в значительной степени усвачвались основные темы правового учения Р. Иеринга, но воспроизведение отличалось оригинальностью творческого замысла и его воплощения. Исследование основано на анализе основных, в том числе редких и малоизвестных, сочинений обочх мыслителей.

Ключевые слова:

Р. Иерине, О.В. Холмс, правовой реализм, понятие права, жизнь права, культурная цель права, история права, борьба за право, цель в праве, право как защищенный интерес, социальный контроль.

\section{Gorban Vladimir Sergeevich}

PhD in Law, Senior Research Fellow, Sector of Legal Philosophy, History and Theory of State and Law, Institute of State and Law, Russian Academy of Sciences

\section{THE INFLUENCE AND INTERPRETATION OF R. IHERING'S LEGAL VIEWS IN THE WORKS OF O.W. HOLMES}

Keywords: R. Ihering, O.W. Holmes, legal realism, concept of law, life of law, cultural purpose of law, history of law, struggle for law, purpose of law, right as a protected interest, social control.

The study examined the influence and interpretation of the legal views of $R$. lhering, one of the most famous German legal scientists of the 19th century, in the works of O.W. Holmes, the founder of the intellectual movement in American legal thought which despite its heterogeneity was generally referred to as legal realism. The analysis of the source-language writings of thinkers revealed the significant similarities of their views as well as the subjects and focuses of legal discussion peculiar to $R$. Ihering and modified and developed by O.W. Holmes. At the same time, the study emphasized that the works of American jurist absorbed the main topics of the legal doctrine of $R$. Ihering to a large extent, but they were original in nature. The study was based on the analysis of major, on the one hand, and rare and little-known, on the other hand, writings of both thinkers.

Прослеживание характера и содержания различных интерпретаций правовых взглядов одного из наиболее влиятельных немецких правоведов Р. Иеринга (1818-1892) имеет существенное значение для расшифровки традиционной иеринговской темы и тематических профилей в объяснении и трактовке сущности и закономерных связей права и правовых явлений. В лице современников и представителей последующих поколений правоведов, философов и социологов права существенные компоненты правового учения Р. Иеринга имели популяризаторов, интерпретаторов, критиков и комментаторов, последователей и сторонников, которые своими оценками и интерпретациями творчества Р. Иеринга редко оставляли равнодушными читателей, способствуя распространению и усвоению творческого наследия известного правоведа. В различных интерпретациях творчества Р. Иеринга, с одной стороны, просматривается та основная тема, главный сюжет, который непосредственно атрибутирован Р. Иерингу и его конкретным теоретическим и историческим воззрениям, а с другой - представлены те вариативные исполнения, воспроизведения, трактовки и модификации, которые легли в основу творчества других правоведов. В связи с этим можно говорить о влиянии и интерпретации творчества мыслителя. В действительности эти моменты развития интеллектуальной мысли часто тесно переплетаются, так что вычленить один из них не представляется возможным.

Показательной в этом отношении является логика интерпретаций правовых взглядов Р. Иеринга в американской правовой литературе. Так, О.В. Холмс (1841-1935), родоначальник движения американских реалистов, судья Верховного суда США, взяв за основу сюжет о борьбе за право, написал в оригинальном метафорическом срезе сочинение о праве как борьбе за право, которая виделась О.В. Холмсу как высокое искусство юридической профессии; историю борьбы за право как историю развития права он истолковал как отражение «панорамы исторической судьбы человека». В дальнейшем эти и многие другие изначально иеринговские фрормулы - 
например, о том, что право детерминируется не логикой, а опытом, - приобрели широкое хождение и активное употребление в различных версиях обращения к творчеству О.В. Холмса и развитии взглядов американских реалистов. Расшифровка различных интерпретаций позволяет, с одной стороны, определить влияние взглядов Р. Иеринга на последующее развитие юридической мысли, а с другой - проследить элементы преемственности и новизны в трактовках права.

В пестрой палитре исследований о формировании и развитии американского правоведения вопрос о влиянии правового учения Р. Иеринга на воззрения одного из основных и наиболее влиятельных представителей так называемого американского правового реализма О.В. Холмса зачастую либо имеет характер общего посыла, т. е. вроде как творчество Р. Иеринга оказало влияние на О.В. Холмса или, как осторожно и многократно повторяет известный американский правовед наших дней Р. Саммерс, «вероятно, оказало влияние» [1], либо вовсе сознательно или бессознательно опускается, а идейные истоки правовых взглядов О.В. Холмса усматривают в возможном влиянии его коллег по так называемому «метафизическому клубу». В действительности интерес О.В. Холмса к творчеству Р. Иеринга был чрезвычайно высок. Последний оказал решительное влияние на формирование правовых взглядов О.В. Холмса. А учитывая широко признанное влияние О.В. Холмса на все последующее развитие правовой мысли в США, можно легко проследить истоки современного американского правоведения, по меньшей мере его значительной части, в творчестве одного из наиболее влиятельных и знаменательных правоведов XIX в. В рамках одной научной статьи невозможно раскрыть все аспекты данной проблематики. В первую очередь ставится вопрос о прояснении на конкретных примерах влияния Р. Иеринга на О.В. Холмса и формировании в связи с этим научно-исследовательской программы американского правоведа.

В американском правоведении Р. Иеринга именуют «полубогом», «немецким Бентамом» [2], «немецким Марком Твеном» и т. п. При этом далеко не все произведения Р. Иеринга были переведены в XIX в. на английский язык. Так, например, О.В. Холмс в своем сочинении «Общее право» (1881) многократно цитировал одно из основных сочинений Р. Иеринга - «Дух римского права» (причем различные тома, отражавшие разные этапы формирования взглядов Р. Иеринга). Однако О.В. Холмс, который превосходно владел также немецким и французским языками, использовал французский перевод сочинения. Если «Борьба за право» была переведена на английский язык в 1879 г., т. е. спустя семь лет после выхода в свет, то, например, «Цель в праве» была переведена на английский язык и издана в США лишь в 1913 г. При этом Э. Бочард отмечал, что английский перевод «Борьбы за право», выполненный Д. Лейлором, был «слабым и плохим» [3, p. 316].

Отсутствие переводов основных сочинений Р. Иеринга, конечно же, создавало препятствия для знакомства широкой читающей публики с основными идеями правового учения Р. Иеринга. Однако это не было препятствием для ведущих американских правоведов, таких как О. Холмс, Р. Паунд, К. Ллевеллин, Дж. Фрэнк, Л. Фуллер и др., которые, в частности, владели немецким языком и читали сочинения Р. Иеринга в оригинале.

Американских правоведов привлекало в учении Р. Иеринга главным образом то, что оно было направлено против застывших, неизменных форм права и правового мышления. Традиционным для практики американского правосудия в этот период было то, что суды отказывали в защите прав и интересов граждан, ссылаясь лишь на отсутствие в общем праве соответствующего прецедента. Инертность правовых понятий и правил, а также консервативное сознание большинства юристов привели к формированию в американском правоведении движения, которое получило название «американский правовой реализм».

Наша современница, известный американский правовед К. Веллс пишет: «Холмс - это один из доминирующих образов американской юриспруденции. Поэтому наши чувства о нем и его моральной позиции являются главными в нашей правовой культуре» [4, р. 550].

О.В. Холмс в труде «Общее право» (1881), вторя Р. Иерингу, сочинения которого (особенно «Дух римского права») он хорошо знал, в частности, писал: «Жизнь права не была логикой; это был опыт» [5, р. 1]; «право воплощает историю национального развития на протяжении многих веков и не может рассматриваться так, как будто оно содержало лишь аксиомы и заключения из учебника по математике» [6].

Позже О.В. Холмс не раз повторял это положение о том, что жизнь права - это не логика и математика, а опыт. Так, в большой статье под названием «Путь права» (1897) он писал следующее: «Заблуждением... является представление, что единственная сила, которая оказывает влияние на развитие права, - это логика» [7, р. 465]. Заблуждением и опасностью является представление, что «данная система, наша например, может быть разработана как математика из общих аксиом поведения» [8].

За несколько десятилетий до этого Р. Иеринг в третьем томе «Духа римского права» (1865) писал: «Любой полный культ логического, который стремится взвинтить юриспруденцию до математики права, является заблуждением и основывается на непонимании сущности права. Не жизнь существует ради понятий, а понятия ради жизни. Не то, что постулирует логика, а то, 
что постулирует жизнь, оборот, правовое чувство, должно происходить, будь это логически необходимо или невозможно» [9, S. 311-312].

P. Иеринг полагал, что состояние права зависит от уровня развития народа, его культуры и т. п. По мнению Р. Иеринга, как не существует лекарства, одинакового для всех болезней, так и не существует права, одинаково пригодного для всех эпох и народов. Такая трактовка права не приводила Р. Иеринга к отрицанию естественного права, бесспорное историческое значение которого Р. Иеринг признавал. Он полагал, что право отражает эволюцию культурных ценностей в истории. В связи с этим он трактовал историческую роль философа права как обладание способностью узреть «прогресс культуры» раньше, чем другие, подобно путнику, идущему навстречу солнцу и видящему лучи восходящего солнца на вершине горы, пока основная масса народа еще спит в долине.

О.В. Холмс также признавал значение социально-культурного и исторического моментов в праве: «Сущность права в любой момент времени довольно близко, насколько возможно, согласуется с тем, что в этот период считают удобным; однако его фрорма и механизм, а также степень тех желаемых результатов, которые оно в состоянии достичь, зависит в значительной степени от его прошлого» [10, p. 1].

В сочинениях О.В. Холмса легко прослеживается критика примата логического в праве, очень схожая с аргументацией Р. Иеринга. О.В. Холмс полагал, что основной задачей права является обращение к реальности, преодоление господства логики в создании права. «Ощущаемые потребности времени, преобладающие моральные и политические теории, институты публичной политики, осознанно или бессознательно, даже предрассудки, которыми судьи делятся с их друзьями-товарищами, - писал О.В. Холмс, - должны были сделать хорошего больше, чем силлогизм в определении правил, которые должны управлять людьми» [11].

Весьма любопытный для прояснения взглядов О.В. Холмса пример преломления социологически ориентированной правовой теории Р. Иеринга содержится в одном из докладов О.В. Холмса 1885 г. Так, О.В. Холмс в докладе, опубликованном под названием «Право» [12], высказал ряд идей, которые, хотя и были сформулированы в стилистически оригинальной манере, при внимательном прочтении и ближайшем сравнении с идеями Р. Иеринга, в частности о роли борьбы как фрактора социального развития и необходимости участия каждого отдельного гражданина в осуществлении этой задачи, а также о том, что лишь благодаря праву человек как социальное существо реализует нравственные (а по Р. Иерингу, равно социальные) условия своего существования, и некоторые другие, обнаруживают очень созвучные моменты по существу ставящихся вопросов и предлагаемых решений.

В связи с этим примечательны слова О.В. Холмса, которые он произносил в докладе «Право», и те метафорические образы, которыми он пересказал «Борьбу за право» Р. Иеринга и некоторые другие правовые взгляды, сфрормулированные еще в «Духе римского права». В воззрениях и интерпретациях О.В. Холмса прослеживается и оригинальное развитие некоторых значимых концептов правовой теории Р. Иеринга. В интерпретации О.В. Холмса борьба за право более акцентировала квинтэссенцию и социальное предназначение именно юридической профессии как своеобразное наставление по профессиональной этике. Одновременно с этим им была также усвоена идея трактовки истории права как эволюции культурных ценностей.

Используя метафорический образ «влюбленного в Право» и уподобляя право женщине, О.В. Холмс писал, что для такого поклонника Права «история важна так же, как и моральная жизнь». «Для него каждый текст, который он расшифровывает, каждое сомнение, которое он разрешает, добавляет новый штрих в раскрывающуюся панораму судьбы человека на этой земле. Его задача не будет решена до тех пор, пока он при максимальном напряжении человеческого воображения не увидит своими глазами рождение и рост человечества, не поймет наиболее глубоко философию своего бытия» [13]. Слова О.В. Холмса о «раскрывающейся через борьбу за Право панораме судьбы человека на этой земле» несомненно были созвучны словам Р. Иеринга о «борьбе за право» в одноименной концепции, о том, что «...каждый человек участвует в работе на своем, пусть даже на очень ограниченном месте, над культурной целью человечества» [14, S. 59], которые он сформулировал в «Цели в праве» и которые были лейтмотивом «Духа римского права».

«Когда я думаю таким образом о праве, - писал О.В. Холмс, - я вижу принцессу более могущественную, чем когда-то властвующую в Байё, вечно вплетающую в свою паутину смутные образы постоянно удаляющегося прошлого - образы слишком тусклые, чтобы их заметили невооруженным глазом, слишком символичные, чтобы их можно было интерпретировать, исключая ее учеников, но доступные проницательному взгляду, обнаруживающему каждый мучительный шаг и каждое сотрясающее мир противоборство, с помощью которых человечество работало и отвоевывало свой путь от дикой первобытной изоляции к органической социальной жизни» [15, p. 31-32].

С другой стороны, продолжал О.В. Холмс, «мы видим ее ежедневно, не как антропологи, студенты или фрилософы, а как участники в той драме, в которой она является провидением и господствующей силой. Когда я думаю о Праве, каким его мы знаем в судах или на рынке, оно представляется мне женщиной, сидящей у дороги, под затеняющим капюшоном которой каждый 
человек увидит лицо своих заслуг и нужд» [16, р. 32]. «Справедливые комбатанты, мужественно отстаивающие свои права, видят, как она ведет списки с суровым и разборчивым взглядом беспристрастного судьи. Негодяй, который ослушался ее самых священных заповедей и думал, что может проскользнуть путями, на которых ее нет, обнаруживает, что его путь заканчивается с ней, и созерцает под ее капюшоном неумолимое лицо смерти» [17].

Анализ другого сочинения О.В. Холмса - «Путь права» (1897) [18, р. 459] показывает, что О.В. Холмс пытался также сформулировать собственное понимание права, которое интерпретировал как «систематизированное прогнозирование рисков». В такой трактовке права проводилась мысль о том, что право - это осуществление социального контроля посредством деятельности судов, которые «находят» в каждом случае право.

В сочинениях американских реалистов эта тема будет в дальнейшем интерпретироваться как то, что право является формой социального контроля. По мнению О.В. Холмса, то, что называется правовой обязанностью, является не чем иным, как прогнозом в отношении того, что если человек делает определенные вещи или воздерживается от чего, то он будет принужден тем или иным путем через осуществление правосудия, - это уже будет субъективным правом. По существу, он задавался вопросом, является ли данный интерес защищенным или нет, даст ли суд этому интересу правовое признание или нет? В систематическом поиске ответа на этот вопрос американский правовед как раз и усматривал основную задачу юридической деятельности. Соответственно, прогнозирование или предугадывание перспективы решения судьи составляет некую сущность права, как полагал О.В. Холмс.

О.В. Холмс рассматривал идею калькулируемых материальных последствий определенного поведения как основную идею права. Иными словами, важной для понимания права, по О.В. Холмсу, является перспектива удовлетворения в первую очередь материальных интересов. Следует отметить, что идея права как юридически защищенного интереса (удовлетворение или перспектива такового) у Р. Иеринга перекликалась с идеей О.В. Холмса о калькулируемых прогнозах и предсказаниях судебного суждения о применении силы в конкретном случае, что сводилось в конечном итоге, как подчеркивал О.В. Холмс, к прогнозированию материальных выгод от судебного решения. Эта тема также была развита Р. Иерингом в «Борьбе за право» в описании эгоистических мотивов осуществления права и социальных действий, а также в «Цели в праве» в трактовке права и вознаграждения как эгоистических мотивов «социальной механики». Важно отметить, что, например, в социологии права М. Вебера одной из центральных была тема «права, калькулируемо функционирующего согласно рациональным правилам». При этом трактовка Р. Иерингом права как защищенного интереса имела значительно более выраженную этическую окраску, чем в последующих версиях социологически ориентированных трактовок права, например того же О.В. Холмса.

О.В. Холмс не ограничивался трактовкой права как калькулируемых прогнозов и рисков применения публичной власти, в первую очередь имея в виду чисто материальные последствия поведения. Весьма схоже с иеринговской трактовкой соотношения права и нравственности как совместно действующих сил и требований О.В. Холмс полагал, что «право - доказательство и внешнее хранилище нашей моральной жизни. Его история - это история морального развития жизни» [19, р. 459]. При этом то, что общество может восстать и бороться против произвольных законов, по мнению О.В. Холмса, доказывает, что «право если не часть нравственности, то ограничивается ею» [20, р. 460].

Сочинения О.В. Холмса оказали существенное влияние на формирование правового мышления нескольких поколений американских правоведов. К. Веллс отмечает, что только за период 1980-1988 гг. было опубликовано более 60 статей в американской правовой научной периодике о О.В. Холмсе и его правовых воззрениях [21, р. 543]. «Холмс является настолько значимым для американской правовой традиции, - пишет К. Веллс, - что понимание того, что Холмс думал о праве, - это важный шаг в понимании наших собственных представлений о правовой теории» [22].

Во всей совокупности взглядов О.В. Холмса прослеживается явный эклектизм. При этом влияние правовых взглядов Р. Иеринга было весьма существенным. Следует отметить также, что творческий стиль О.В. Холмса отличался высокими литературными способностями, но при этом был очень схож с характером творческого стиля Р. Иеринга, что легко обнаруживается при сравнении и сопоставлении взглядов мыслителей.

Проведенный анализ позволяет сделать следующие выводы.

- Правовые взгляды Р. Иеринга, артикулированные в широком спектре разнообразных оригинальных теоретических и методологических концепций и установок - структурно-фрункционального и эмпирико-аналитического анализа социальной действительности как источника и среды верификации права, утверждения примата социальной обусловленности права над его логической структурой, юридической техники как искусства нормативно-текстуальной и логикопонятийной рефлексии социальных интересов, потребностей и целей, правовой социализации и правовой идентификации личности и многих других, - оказали существенное влияние на формирование ряда последующих школ и направлений в юридической науке, особенно в США (О. Холмс, Р. Паунд, К. Ллевеллин, Л. Фуллер и др.). 
- Поскольку в воззрениях О.В. Холмса правовые идеи Р. Иеринга не только воспроизводились, но и подвергались оригинальной стилистической модификации, дальнейшей разработке и популяризации, это в значительной степени способствовало формированию взглядов представителей движения американского правового реализма, так как О.В. Холмс был основателем и одним из главных представителей этого направления. Особенно показательно при этом, что Р. Иеринг самотипологизировал свое учение как реалистическое.

- В качестве значимого аргумента столь глубокого восприятия, усвоения и разработки традиционной иеринговской проблематики в сочинениях О.В. Холмса может рассматриваться сходство взглядов по следующим вопросам: критика антифоомализма и консерватизма в юридической науке и практике; преодоление инертности судов в защите прав, так как американские суды, как правило, отказывали в защите, ссылаясь на отсутствие подходящего прецедента, но теперь вводился фрактор интереса, а суд в новой реалистической парадигме интерпретировался как орган социального контроля; роль юристов в «добывании» и «отыскивании» права в жизни и некоторым другим.

- По характеру интерпретации правовых взглядов Р. Иеринга в сочинениях О.В. Холмса можно определенно говорить о формальной реконструкции оригинальных идей, установок и концептов, тем и сюжетов, атрибутированных творчеству немецкого правоведа, что проявлялось в объективно-структурной (как правило, вне контекстного содержания) расшифровке и прочтении текстов Р. Иеринга.

\section{Ссылки:}

1. Summers R.S., McRoberts W.G., Goodhart A.L. Rudolf von Jhering's Influence on American Legal Theory // Summers R.S. Essays in Legal Theory. Ch. 2. 2000. P. 21-42. https://doi.org/10.1007/978-94-015-9407-3_2.

2. Ihering R. Law as a Means to an End / transl. from the German by I. Husik ; with an editorial preface by J.H. Drake and with introductions by H. Lamm and W.M. Geldart. Boston, 1913. 560 p.

3. Borchard E. Jurisprudence in Germany // Columbia Law Review. 1912. Vol. 12, no. 4. P. 301-320. https://doi.org/10.2307/1110797.

4. Wells C. Legal Innovation within the Wider Intellectual Tradition: The Pragmatism of Oliver Wendell Holmes, Jr. // Northwestern University Law Review. 1988. Vol. 82, no. 3. P. 541-595.

5. Holmes O.W. The Common Law. Boston, 1881. XVI, 422 p.

6. Ibid. P. 1.

7. Holmes O.W. The Path of the Law // Harvard Law Review. 1897. Vol. X, no. 8. March 25. P. $457-478$. https://doi.org/10.2307/1322028.

8. Ibid. P. 465 .

9. Jhering R. Geist des römischen Rechts auf den verschiedenen Stufen seiner Entwicklung. Th. 3, Abth. 1. Leipzig, 1865. X, $342 \mathrm{~S}$.

10. Holmes O.W. The Common Law. P. 1.

11. Ibid.

12. Holmes O.W. The Law. Suffolk Bar Association Dinner, February 5, 1885 [Электронный ресурc]. URL: http://library.law.harvard.edu/suites/owh/index.php/item/43198537/1 (дата обращения: 03.01.2019).

13. Ibid.

14. Jhering R. Der Zweck im Recht. Bd. 1. 4. Aufl. / Erste Ausg. in volkstümlicher Gestalt. Leipzig, 1904. XX, 445 S.

15. Holmes O.W. The Law. P. 31-32.

16. Ibid. P. 32

17. Ibid.

18. Holmes O.W. The Path of the Law. P. 459.

19. Ibid.

20. Ibid. P. 460

21. Wells C. Op. cit. P. 543

22. Ibid.

\section{References:}

Borchard, E 1912, 'Jurisprudence in Germany', Columbia Law Review, vol. 12, no. 4, pp. 301-320, https://doi.org/10.2307/1110797.

Holmes, OW 1881, The Common Law, Boston, XVI, 422 p.

Holmes, OW 1885, The Law. Suffolk Bar Association Dinner, February 5, 1885, viewed 3 January 2019, <http://library.law.harvard.edu/suites/owh/index.php/item/43198537/1>.

Holmes, OW 1897, 'The Path of the Law', Harvard Law Review, vol. X, no. 8, March 25, pp. 457-478, https://doi.org/10.2307/1322028.

Ihering, R 1913, Law as a Means to an End, Boston, $560 \mathrm{p}$.

Jhering, R 1865, Geist des römischen Rechts auf den verschiedenen Stufen seiner Entwicklung, vol. 3, pt. 1, Leipzig, X, 342 S., (in German).

Jhering, R 1904, Der Zweck im Recht, bk. 1, 4th ed., Leipzig, XX, 445 S., (in German).

Summers, RS, McRoberts, WG \& Goodhart, AL 2000, 'Rudolf von Jhering's Influence on American Legal Theory', in RS Summers, Essays in Legal Theory, ch. 2, pp. 21-42, https://doi.org/10.1007/978-94-015-9407-3_2.

Wells, C 1988, 'Legal Innovation within the Wider Intellectual Tradition: The Pragmatism of Oliver Wendell Holmes, Jr.', Northwestern University Law Review, vol. 82, no. 3, pp. 541-595. 